\title{
MORFOLOGI KOTA SOLO (TAHUN 1500-2000)
}

\author{
Qomarun \\ Dosen Jurusan Teknik Arsitektur Fakultas Teknik, Universitas Muhammadiyah Surakarta \\ E-mail: qomarun@ums.ac.id \\ Budi Prayitno \\ Dosen Jurusan Teknik Arsitektur Fakultas Teknik, Universitas Gadjah Mada, Yogyakarta \\ E-mail: budiprayitno@ugm.ac.id
}

\begin{abstract}
ABSTRAK
Paper ini berusaha mengupas tentang perubahan struktur dan bentuk Kota Solo setelah mengalami perkembangan dari masa ke masa. Metode penelitian dilakukan dengan studi pendekatan kearsipan, baik arsip primer, arsip sekunder maupun arsip fisik. Untuk arsip primer bersumber pada naskah-naskah dokumenter Jawa, seperti parintah, undang-undang, pranatan, piyagem, kakancingan, serat, gugat, penget dan babad. Untuk arsip sekunder bersumber pada buku-buku dari para ahli sejarah (Ricklefs, Lombard, Vorstensteden, Muljana, Notosusanto, Kartodirdjo dll) dan hasil riset dari para ahli sejarah arsitektur Jawa (Ronald, Ikaputra, Adishakti dll). Untuk arsip fisik bersumber dari artefak, elemen alam dan tradisi masyarakat yang diperoleh dari survey lapangan. Temuan utama dari studi morfologi Kota Solo pada tahun 1500-2000 adalah, elemen 'tulang' telah tumbuh membentuk berbagai formasi, yaitu memusat, mengelompok dan organik. Elemen 'daging' telah tumbuh secara horisontal, vertikal dan interestisial. Sementara elemen 'darah' telah berkembang dari orangorang pribumi (Jawa, Madura, Banjar) bertambah dengan orang-orang pendatang (Cina, Arab, India, Belanda), dengan mata pencaharian dari agricultural ke non-agricultural. Temuan penting lainnya adalah, Kota Solo tersusun oleh tiga konsep yang berlainan, yang saling tumpang tindih, yaitu konsep organik oleh masyarakat pribumi, konsep kolonial oleh masyarakat Belanda dan konsep kosmologi oleh masyarakat Keraton Jawa. Kota Solo pada tahun 1500-1750 masih berupa kota tepian sungai di Bengawan Solo, kemudian pada tahun 1750-1850 berkembang menjadi kota campuran antara kota perairan dan daratan. Sejak tahun 1850an, Kota Solo mulai meninggalkan lalu lintas sungai dan berganti ke lalu lintas daratan, sehingga menjadi kota daratan. Apalagi sejak tahun 1900an, setelah dibangun teknologi baru pada sarana transportasi dan utilitas kota, yaitu jalur rel kereta api, jalur trem, jaringan listrik dan jaringan air bersih, maka Kota Solo benar-benar telah berubah ke kota daratan, meninggalkan hiruk-pikuk kota tepian sungai yang pernah terjadi di Bengawan Solo. Pada tahun 2000an, Kota Solo mengalami permasalah kota yang umumnya juga terjadi di kota-kota besar di Indonesia, yaitu permasalahan pada lingkungan alaminya, lingkungan buatannya dan lingkungan humannya. Akumulasi permasalahan kota itu menjadikan Kota Solo pada masa-masa mendatang akan semakin memasuki masa ke arah decline, sehingga perlu dicarikan grand-design kota yang sustainable.
\end{abstract}

Kata kunci: morfologi, irreversible, kota, bentuk, struktur.

\section{ABSTRACT}

The purpose of this study is to explore the transformation of city form and its structure in Solo which has developed from time to time. The method of this research was carried out by a-three-archive research strategy as follows: primary files; secondary files and physical files. The primary files referred to the old Javanese documentary (examples: parintah, undhangundhang, pranatan, piyagem, kakancingan, serat, gugat, penget, babad). The secondary files referred to the document of local, national and international historians (examples: Ricklefs, Lombard, Vorstensteden, Muljana, Notosusanto, Kartodirdjo, Sajid) and Javanese architecture researchers (Ronald, Ikaputra, Adishakti). While the physical files referred to the field research that was conducted by interviews and collecting the artefacts. The main findings of study of morphology in the city of Solo were: the 'skeleton' element grew in three formations (central, cluster and organic); the 'meat' element grew in three formations also (horizontal, vertical, and interstitial); and the 'blood' element increased from the native people (Javanese, Madura, Banjar) to foreign people (Chinese, Arab, India, Dutch) and changed from agricultural to nonagricultural activities. The other findings were the city of Solo was constructed by a-three-concept of urban design as follows: the organic concept which was conducted by native people; the colony concept which was conducted by the Dutch; and the cosmology concept which was conducted by the Javanese Kingdom. In 1500s-1750s, initially the city of Solo was a settlement grew at the bank of Bengawan Solo. Afterwards, in 1750s-1850s it developed into a combined water-and landbased urban fabric Since 1850s, the city of Solo has left the river transportation and changed into the land transportation. Moreover, in 1900s the city of Solo built the new technology of transportation and urban utilities as follows: train, tram (streetcar), electricity and water city installations. In 2000s, the city of Solo acquired the city problems like the other cities in Indonesia. The city problems were divided into three aspects as follows: the built environment; the natural environment; and the social environment. The accumulation of those problems made the city grow in decline direction that needs to be fixed by a-sustainable-city design.

Keyword: morphology, irreversible, city, form, structure. 


\section{PENDAHULUAN}

Kota Solo merupakan salah satu kota tua di Indonesia yang menyimpan berbagai peninggalan kebudayaan dari bermacam etnik, baik pada jaman sejarah maupun prasejarah. Penemuan Pithecanthrophus Soloensis oleh W.F. Oppennorth dan C. Ter Haar (Kartodirdjo, 1975) di tepian Bengawan Solo dapat membuktikan bahwa manusia purba telah pernah hidup di wilayah Solo pada masa prasejarah. Sementara itu, peninggalan pada masa sejarah, seperti candi, keraton, pura maupun bangunan-bangunan kuno masih dapat dijumpai di berbagai sudut Kota Solo. Pada saat sekarang ini, ruang Kota Solo selain dibentuk oleh bangunan-bangunan modern seperti kota-kota lainnya di Indonesia, maka secara arsitektural ruang kotanya masih mampu memperlihatkan bangunan-bangunan yang bercirikan era kerajaan (feodal) Jawa dan era kolonial Belanda, bahkan pada beberapa bagian kota masih terdapat bangunan-bangunan dengan arsitektur etnik Cina, Arab dan Indoland/ Campuran.

Kehadiran dua nama, yaitu 'Surakarta' dan 'Solo', menambah keunikan tersendiri bagi eksistensi kota tua ini. 'Solo' diambil dari nama tempat bermukimnya pimpinan kuli pelabuhan, yaitu $K i$ Soroh Bau (bahasa Jawa, yang berarti kepala tukang tenaga) yang berangsur-angsur terjadi pemudahan ucapan menjadi Ki Sala, yang berada disekitar Bandar Nusupan semasa Kadipaten dan Kerajaan Pajang (1500-1600). Sementara 'Surakarta' diambil dari nama dinasti Kerajaan Mataram Jawa yang berpindah dari Kraton Kartasura pada tahun 1745. Perpindahan kraton dilakukan oleh Raja Paku Buwono II karena Kraton Kartasura sudah hancur akibat peperangan dan pemberontakan yang terkenal dengan Geger Pecinan tahun 1742. Pemberian nama kraton baru dengan membalikkan suku kata dari nama kraton lama, yaitu dari 'Karta-Sura' menjadi 'Sura-Karta', sampai sekarang sudah menjadi cerita umum masyarakat Solo.

Perubahan Kota Solo dari masa ke masa dapat dilihat berdasarkan beberapa peta lama yang diperoleh dari arsip-arsip di Belanda dan di Solo, seperti contoh berikut (lihat gambar 1):

Solo dan bahkan juga ke anak-anak sungainya. Pada awalnya, di Solo sendiri terdapat empat bandar yang ramai saat itu, yaitu Bandar Kabanaran di Laweyan, Bandar Pecinan di Kali Pepe, Bandar Arab di Kali Jenes dan Bandar Nusupan di Semanggi. Setelah terjadi pendangkalan pada anak-anak sungai Bengawan Solo (Kali Jenes, Kali Kabanaran dan Kali Pepe), maka bandar-bandar yang ada padanya akhirnya tidak dapat berfungsi lagi, dan diganti Sedangkan perkembangan dan perubahan bentuk kota (morfologi kota), berdasarkan arsip primer, sekunder dan fisik, dapat dijelaskan seperti uraian dan gambargambar berikut.

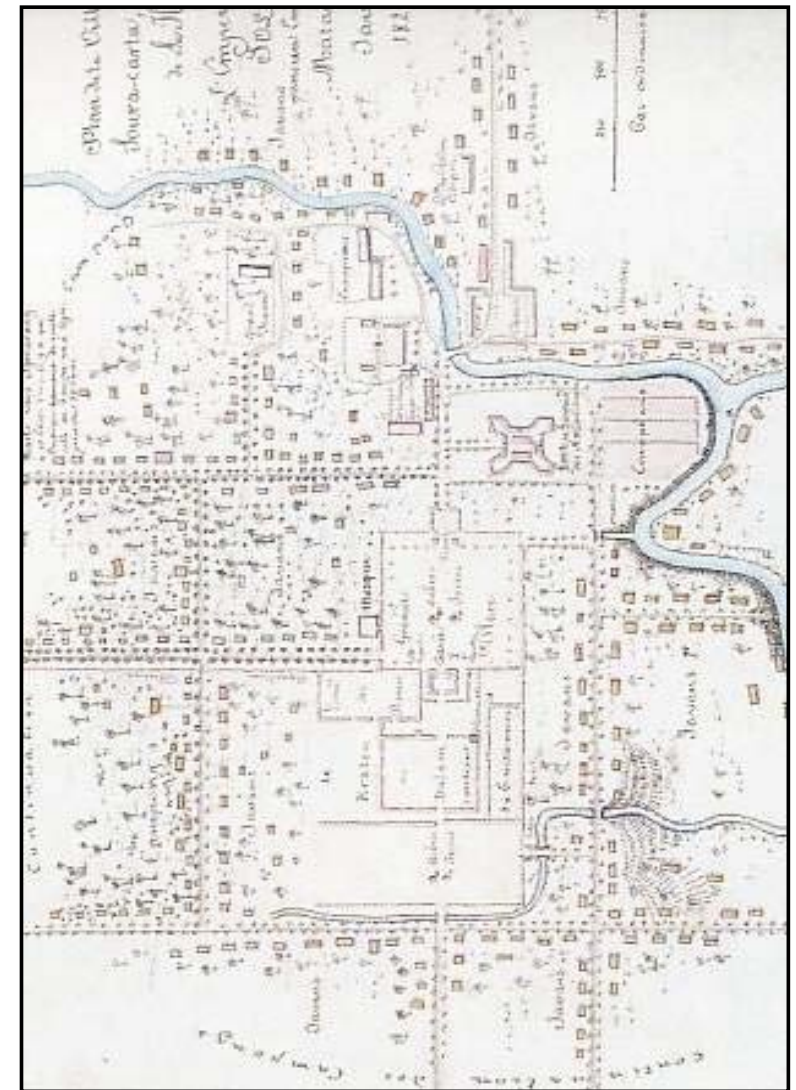

1821

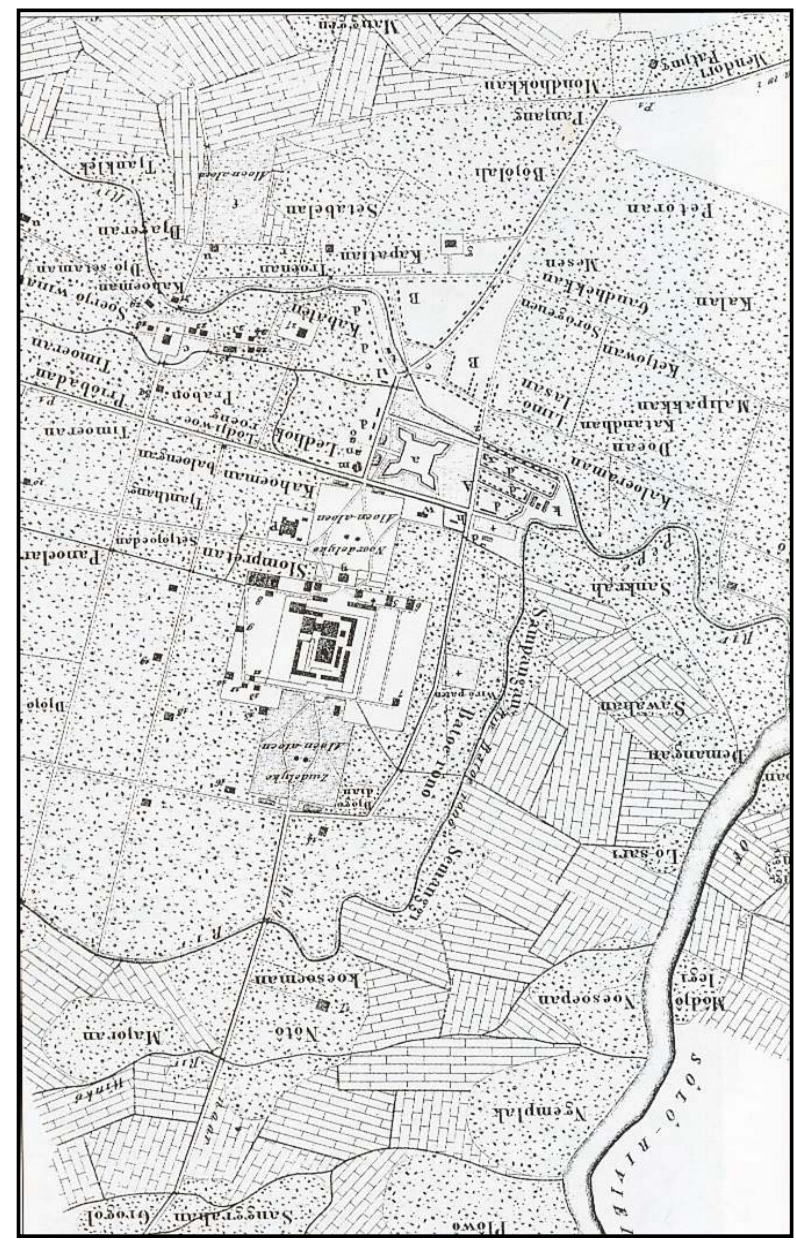

1853 


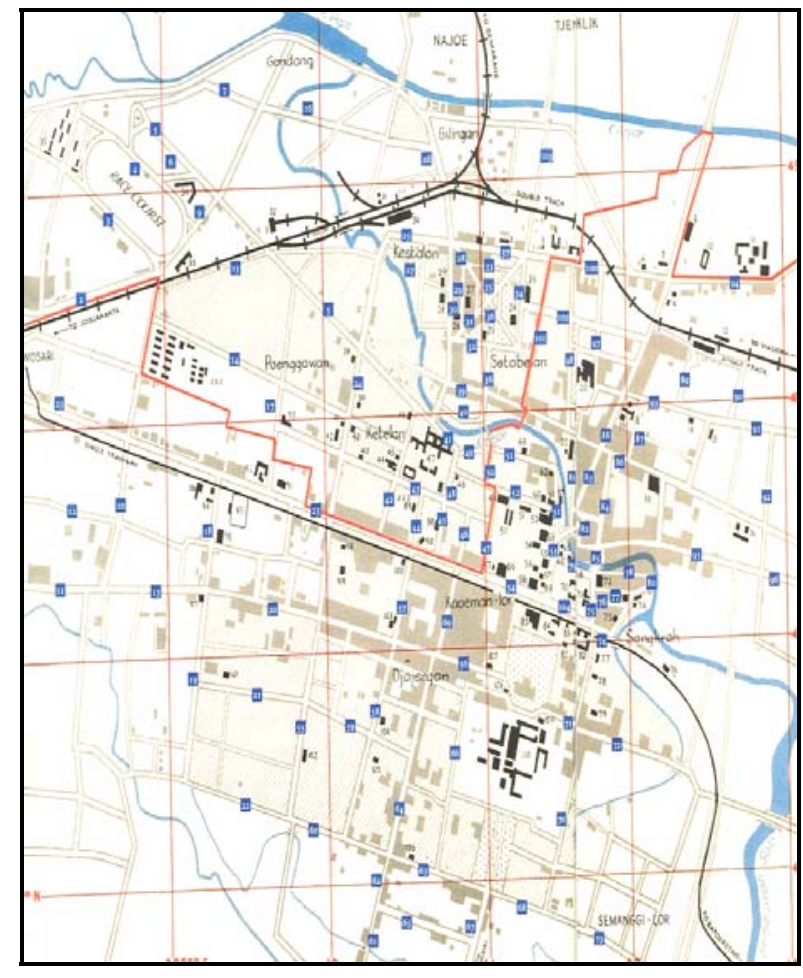

1945

Sumber: Vorstensteden, 1998

\section{Gambar 1. Peta-Peta Solo Lama}

\section{PERKEMBANGAN KOTA SOLO 1550-1745}

Pada interval masa ini, secara fisik Kota Solo sedang berubah dari masa embrio ke masa berkembang. Kota Solo pada awalnya dibentuk oleh masyarakat kuli (bahasa Jawa: soroh bau hingga pimpinannya disebut ki-soloh atau ki-solo atau kisala) yang berada di Bandar Nusupan. Mereka tinggal di tepi Bengawan Solo, di dekat pelabuhan dimana mereka bekerja untuk majikannya yang ada di Kadipaten Pajang (1530-an), sehingga membentuk pemukiman tepian sungai (semacam water-front setlement). Kadipaten Pajang, yang kemudian menjadi Kerajaan Pajang (sejak 1568) adalah penerus Kerajaan Demak (1500-1546), kerajaan Islam pertama di Jawa. Namun pada tahun 1582, kerajaan ini berpindah ke Kota Gede dan menjadi Kerajaan Mataram. Kebutuhan pokok kehidupan pemerintahan pada masa Kerajaan Pajang banyak disuplai dari lalu lintas sungai dan bandar-bandar yang berada di sepanjang Bengawan Solo (ada 44 bandar dari SoloSurabaya). Kapal-kapal besar dari pesisir Jawa dan selat Malaka saat itu mampu mengadakan perjalanan sampai ke pedalaman Jawa melalui Bengawan lalu lintas darat.

\section{PERKEMBANGAN KOTA SOLO 1745-1821}

Pada interval waktu ini terjadi peristiwa besar di Solo, yaitu masuknya kolonial Belanda dan juga
Keraton Mataram dari Kartasura. Keraton Mataram yang semula di Kota Gede telah berpindah tiga kali, yaitu ke Kerta (1601), Plered (1613) dan Kartasura (1677), dan kemudian kembali ke Solo (Mataram adalah penerus Pajang, yang semula ada di daerah Solo, seperti uraian di atas). Perpindahan keraton harus dilakukan oleh PB II saat itu karena istana yang lama telah hancur oleh tiga kali peperangan, yaitu pada saat terjadi Geger Pacinan (1742), peperangan Cakraningrat (1742) dan peperangan Belanda/PB II melawan Cakraningrat (1742). Setelah dilakukan survey pemilihan lokasi untuk keraton, maka dipilih Desa Sala (usul Hohendorff) sebagai tempat berdirinya keraton (alternatif lain untuk lokasi keraton saat itu adalah Talawangi dan Sanasewu). Dengan dipilihnya Desa Sala sebagai lokasi keraton, maka tentu hal ini membawa pengaruh yang sangat besar bagi perkembangan Kota Solo ke masa-masa berikutnya. Belanda dan Mataram berdasarkan kepentingan masing-masing, mempunyai power yang sangat besar untuk mengaplikasikan segala konsep tata-kotanya ke dalam bentuk nyata. Belanda dengan konsep kota koloni dan keraton dengan konsep kota kosmologi saling bertumpang tindih membentuk Kota Solo menjadi khas dan unik. Kondisi tersebut juga ditambah lagi dengan pola kota organik yang telah lama disusun oleh masyarakat pribumi. Jadi pada tahap berikutnya, kota tepian sungai yang pernah disusun oleh masyarakat pribumi akan berpadu dengan kota daratan yang berpola sakralprofan (oleh model keraton) dan pola kokohfungsionalis (oleh model Belanda). Pada masa berikutnya, setelah keraton Mataram terpecah menjadi dua kerajaan (1755: Kasunanan dan Kasultanan), tiga kerajaan (1757: Kasunanan, Kasultanan dan Mangkunegaran) dan kemudian empat kerajaan (1812: Kasunanan, Kasultanan, Mangkunegaran dan Pakualaman), maka daerah Solo terpecah menjadi dua wilayah, yaitu wilayah Kasunanan dan Mangkunegaran. Sehingga perkembangan struktur kota pada masa berikutnya bertambah lagi menjadi kota yang mempunyai dua wilayah berkonsep kosmologi Jawa. Sementara itu, kampungkampung Jawa juga tumbuh secara memusat mengikuti perkembangan kekuatan dua raja Solo tersebut. Kampung Cina dan Kampung Arab juga berkembang di bekas bandarnya masing-masing. Pada sisi yang lain, kampung Belanda/Eropa mulai tumbuh di dalam benteng Vastenburg dan kemudian menyusul di luaran benteng setelah semakin banyak pendatang barunya.

\section{PERKEMBANGAN KOTA SOLO 1821-1857}

Seiring dengan semakin banyaknya penghuni di pemukiman Eropa (Belanda, Inggris) dan Timur Asing (Cina, Arab, India), maka dibutuhkan pula fasilitias-fasilitas selain rumah tinggal, yaitu tempat 
ibadah, tempat sekolah, tempat jual-beli kebutuhan, tempat mengurusi kependudukan dan lain-lain. Oleh karena itu, Kota Solo pada interval ini sudah berkembang ke arah kota perkantoran (administrasi dan asuransi) dan perdagangan (toko, gudang, pasar). Kota Solo saat itu dipandang oleh masyarakat asing (Belanda, Cina, Arab, India) semakin kondusif sebagai wadah kegiatan masing-masing. Hal ini terlihat dengan adanya bangunan kantor, sekolahan, gereja, gudang yang mulai dibangun oleh Belanda, selain tentu saja pemukiman Eropa. Pada sisi yang lain, banyaknya toko-toko yang dibangun oleh masyarakat Cina dan Arab/India pada rentang waktu ini dapat menjelaskan adanya keamanan dan ketentraman masing-masing kelompok.

\section{PERKEMBANGAN KOTA SOLO 1857-1900}

Perubahan terbesar pada masa interval ini adalah telah diketemukannya teknologi transportasi darat dengan kereta api. Sistem baru ini tentu mampu mengubah pardigma berlalu lintas yang semula masih sebagian di sungai sebagaian di darat, kemudian dapat beralih total ke darat. Selain itu, kondisi sungai-sungai di Solo juga sudah terjadi pendangkalan, sehingga sulit dilalui kapal-kapal besar. Sistem tanam paksa yang pernah dimunculkan pada tahun 1830, berakibat gundulnya hutan-hutan di daerah hinterland, sehingga secara akumulatif tanah-tanah daratan yang longsor dan berguguran di sungai mejadi mengendap dan mendangkalkan sungai. Kota Solo yang secara geografis terletak di lembah dan tempuran sungai, tentu mudah sekali terjadi banjir. Maka pada interval ini, pihak Belanda, bersama-sama Kasunanan dan Mangkunegaran melakukan proyek besar penganggulangan bahaya banjir, baik berupa pembuatan kanaal, pembuatan sungai baru atau pembuatan tanggul. Pada bagian utara kota, Kali Pepe dipotong oleh sungai baru, yang kemudian disebut sebagai Kali Anyar, sehingga air bah tidak memasuki kota melainkan dialirkan melalui luar kota, dan mengikuti Kali Anyar yang bermuara di Bengawan Solo. Pada bagian selatan kota, Kali Laweyan juga dipotong oleh sungai baru dan ditambahi dengan tanggul yang menuju Bengawan Solo, yang kemudian disebut sebagai Kali Tanggul, yang berfungsi menahan air bah dari Kali Laweyan. Sedangkan pada sisi timur kota, dibangun tanggul yang mendampingi Bengawan Solo, sehingga luapan air sungai ketika banjir tidak masuk kota. Proyek ini mengingatkan kita pada penyelesaian kasus-kasus kota di Belanda tentang masalah banjir.

\section{PERKEMBANGAN KOTA SOLO 1900-1945}

Perubahan terbesar pada interval ini adalah dibangunnya berbagai utilitas kota yang modern, yaitu jaringan listrik (tahun 1902 oleh Solosche
Electriciteits Maatschappij atau S.E.M.), jaringan air bersih (tahun 1926 oleh N.V. Hoogdruk Waterleiding atau N.V.H.W.), jaringan KA dan trem (tahun 1905 oleh Staats Spoorwagen atau S.S. dan Nederlandsch Indische Spoorwagen atau N.I.S.) dan pembangunan jembatan antar kota yang melintasi Bengawan Solo, yaitu Jembatan Jurug yang menuju Karanganyar dan Jembatan Bacem yang menuju Sukoharjo (tahun 1915). Pada sisi yang lain, penduduk yang mulai ramai dan padat telah ditambahi fasilitas hiburan dan olah raga, yang umumnya baru pertama dibangun di Indosesia saat itu, yaitu gedung bioskop, gedong pertunjukan Jawa (wayang, kethoprak, kerawitan), gedung pertemuan, stadion sepak bola, lapangan berkuda, taman-taman kota dan stasiun radio.

\section{PERKEMBANGAN KOTA SOLO 1945-2000}

Perubahan terbesar pada masa interval ini adalah terjadinya pergolakan politik dan sosial, serta perubahan lingkungan alam yang berpengaruh buruk kepada ruang kota. Pada tahun 1948 terjadi peristiwa Clash II, yang terkenal dengan politik bumi hangus, sehingga banyak bangunan di Solo yang hancur oleh kemarahan Belanda. Pada tahun 1966 terjadi banjir besar di Solo sehingga separoh Kota Solo tenggelam oleh kedahsyatan Bengawan Solo. Pada tahun 1970an, terjadi boom industri di sekitar Bengawan Solo, sehingga limbah industrinya, yang dibuang ke Bengawan Solo, mampu memusnahkan berbagai spesies mahluk hidup dan hanya menyisakan ikan sapu-sapu. Pada tahun 1980-an, setelah terjadi urbanisasi dan industrialisasi, maka Kota Solo mengalami urban sprawl (pemekaran kota), baik di sisi utara, timur, selatan dan barat. Pembangunan perumahan (real estate, perumnas, komplek hunian baru) mulai menjamur dipinggiran Kota Solo. Pada pusat kotanya, terutama daerah CBD, berkembang pemaksaan bentuk joglo (penjogloan), meskipun mempunyai tipe berlantai banyak. Pada sisi yang lain, Kota Solo yang semula hanya mempunyai fasilitas pendidikan sampai SMA, kini mulai ada dibangun fasilitas untuk jenjang pendidikan yang lebih tinggi, yaitu perguruan tinggi. Pada akhir tahun 1980-an, pemerintah mencanangkan program Paket November 1988, yang berdampak pada menjamurnya bank-bank swasta di Kota Solo. Pada tahun 1990-an, setelah pemerintah mencanangkan program Paket Juli 1993 (eksploitasi wisata), maka banyak bangunan hotel bermunculan, melengkapi perkantoran dan perdagangan. Pada tahun 1998, terjadi peristiwa kerusuhan masal yang menyebabkan bangunan-bangunan hangus dan hancur, seperti terjadi pada saat Clash II tahun 1948. 
DIMENSI TEKNIK ARSITEKTUR Vol. 35, No. 1, Juli 2007: 80 - 87
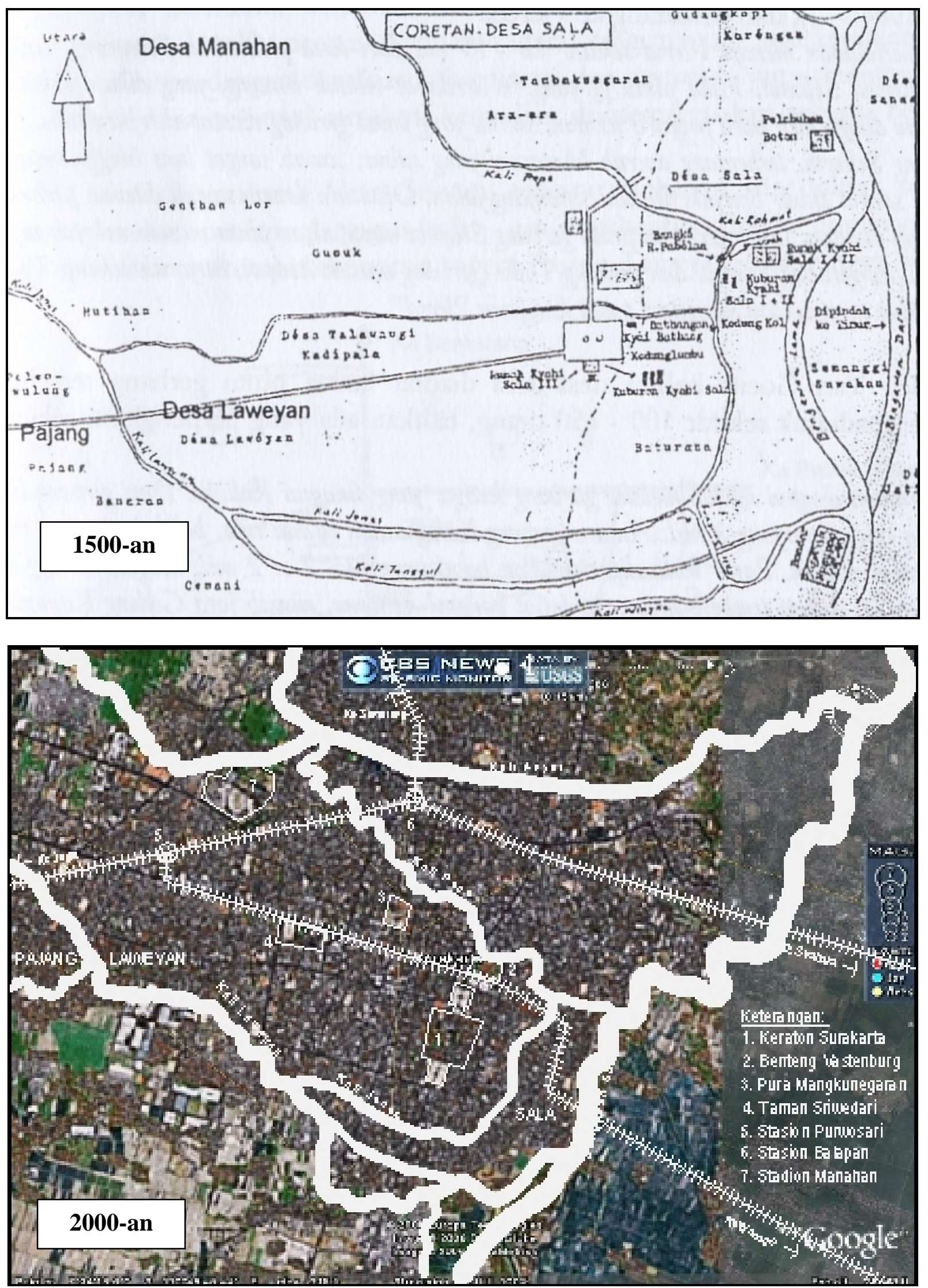

Sumber: Rekonstruksi dari Sajid, 1984 dan earth.google.com, 2006

Gambar 9. Perkembangan Struktur Kota Solo Tahun 1500-2000: Peta Desa Sala Tahun 1500-an sebagai Embrio Kota Solo (atas) dan Peta Struktur Kota Solo Tahun 2006 Dilihat dari Foto Satelit NASA (bawah) 


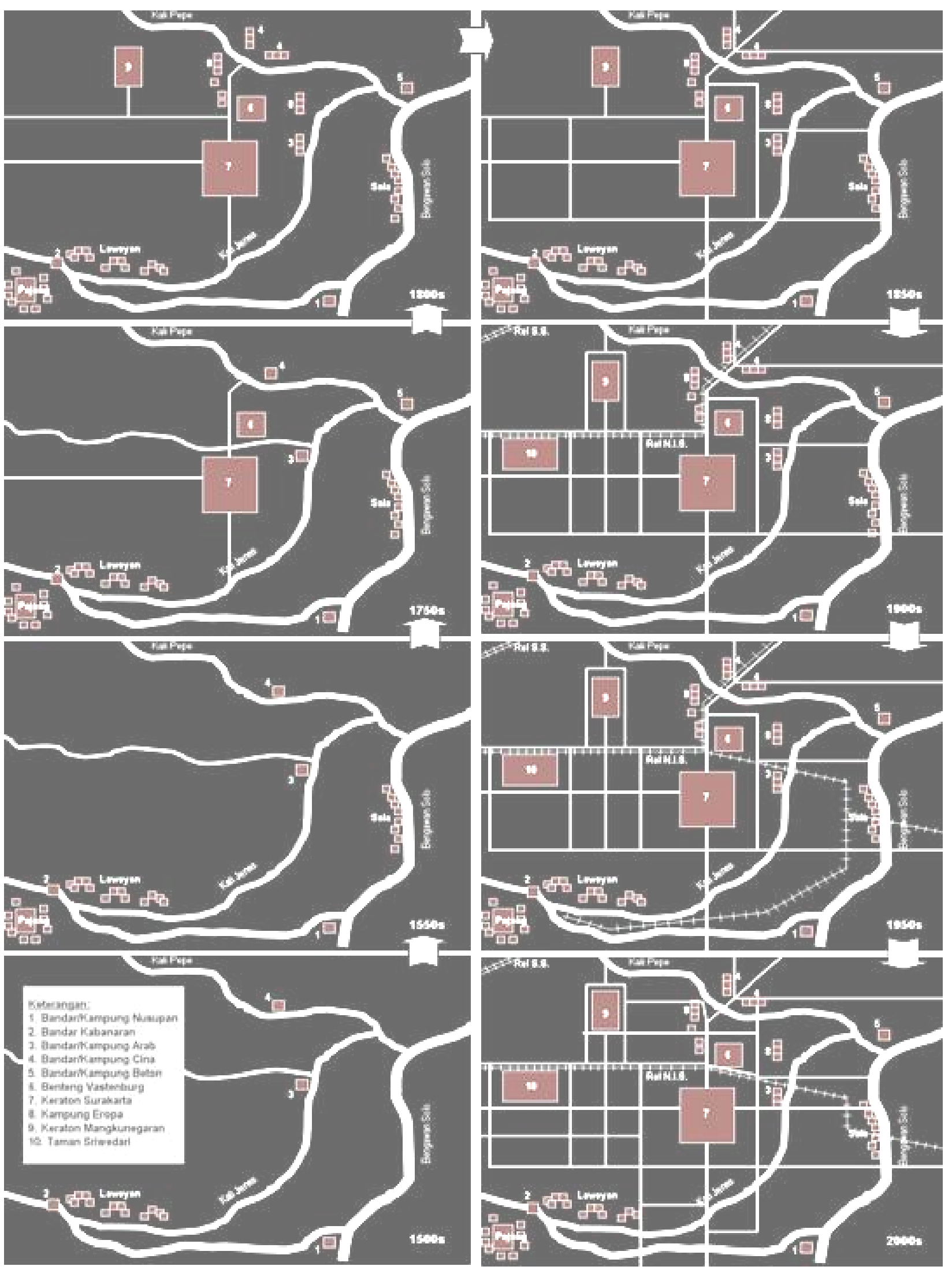

Sumber: Pengolahan Penulis, 2007

Gambar 10. Morfologi Kota Solo 1500-2000: Kampung Pribumi berkembang di Kraton Pajang, Kasunanan, Mangkunegaran dan Desa Sala; Kampung Eropa di sekitar Benteng Vastenburg; Kampung Cina di sekitar Bandar Pepe; dan Kampung Arab di sekitar Bandar Jenes 

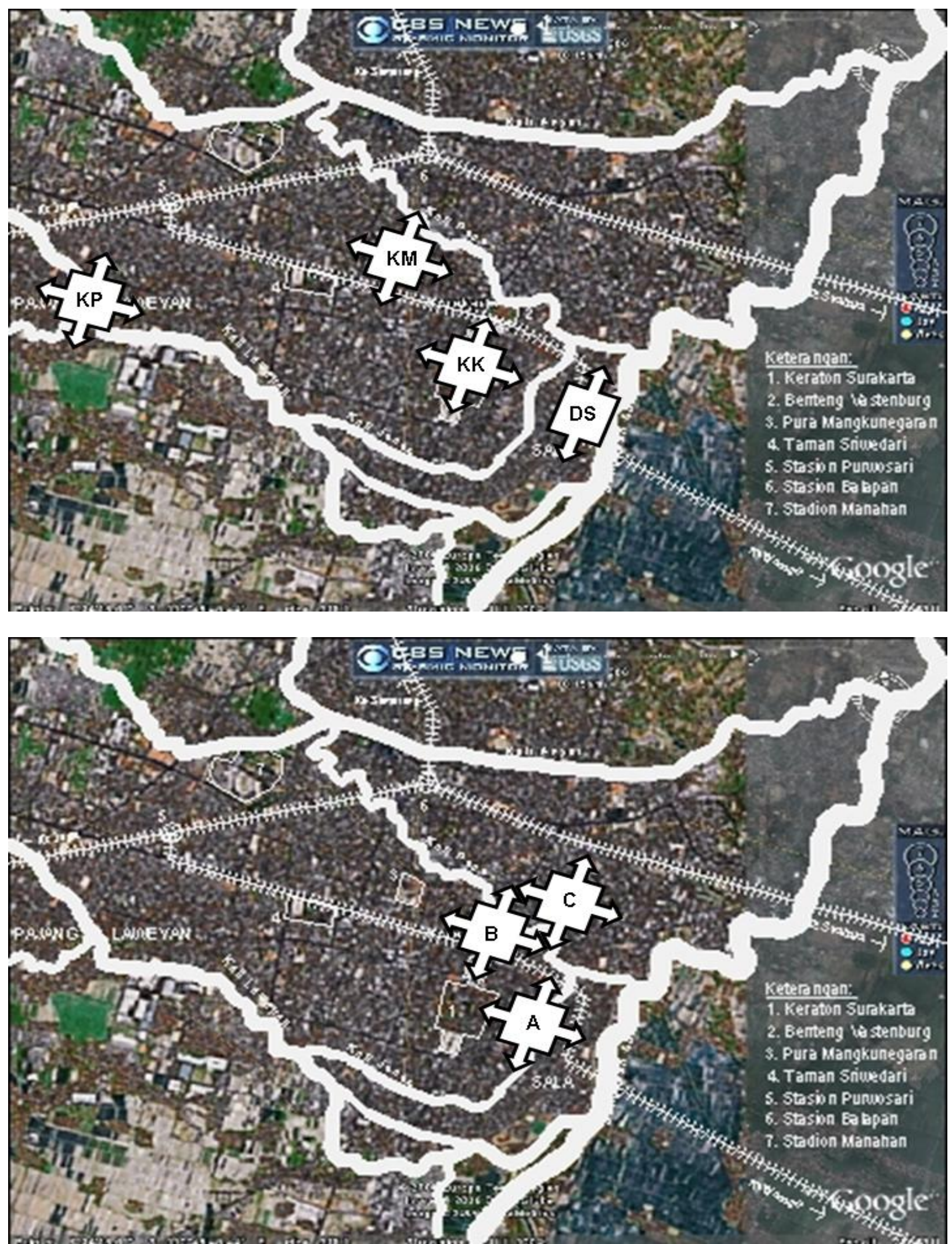

Sumber: Pengolahan Penulis, 2007

Gambar 11. Sejarah dan Perkembangan Permukiman di Kota Solo: Kampung Pribumi (gambar atas) berkembang di: Kraton Pajang (KP); Kraton Kasunanan (KK); Kraton Mangkunegaran (KM); dan Desa Sala (DS), sedangkan Kampung Non-Pribumi (gambar bawah) berkembang di: Bandar Jenes untuk Kampung Arab (A); Benteng Vastenburg untuk Kampung Belanda/Eropa (B); Bandar Pepe untuk Kampung Cina (C) 


\section{PENUTUP}

Morfologi Kota Solo telah mengalami proses perubahan selama 500 tahun. Kota yang umumnya tumbuh secara irreversible, secara biologis tersusun atas tiga elemen utama, yaitu 'tulang' (utilitas kota: jalan, rel, riol), 'kulit' (bangunan hunian: rumah, pasar, gedung kantor, sekolah, rumah sakit) dan 'darah' (aktivitas manusia: bekerja, bepergian, berkumpul). Temuan utama dari studi kasus di Kota Solo pada tahun 1500-2000 adalah, elemen 'tulang' telah tumbuh membentuk berbagai formasi, yaitu memusat, mengelompok dan organik. Elemen 'kulit' telah tumbuh secara horisontal, vertikal dan interestisial. Sementara elemen 'darah' telah bertambah dari orang pribumi (Jawa, Madura, Banjar), orang pendatang (Cina, Arab/India, Belanda,) dan orang priyayi (keturunan raja-raja Jawa).

Temuan penting lainnya adalah, Kota Solo tersusun oleh tiga konsep yang berlainan, yang saling tumpang tindih, yaitu konsep organik oleh masyarakat pribumi, konsep kolonial oleh masyarakat Belanda dan konsep kosmologi oleh masyarakat kraton Jawa. Pada tahun 2000-an, Kota Solo telah mengalami permasalah kota yang umumnya juga terjadi di kota-kota besar di Indonesia, yaitu pada lingkungan alaminya, lingkungan buatannya dan lingkungan sosialnya. Akumulasi permasalahan kota itu menjadikan Kota Solo pada masa-masa mendatang memasuki masa decline.

Sementara struktur kota berdasarkan elemen land telah berkembang dari kota air ke kota daratan. Untuk elemen buildings juga telah berkembang dari tradisional, vernakuler, campuran dan kontemporer. Untuk elemen human juga telah berkembang dari pribumi-agraris, non pribumi-non agraris hingga campuran keduanya. Rekomendasi model inovasi perancangan kota masa depan berdasarkan karakter struktur kotanya, cenderung berbentuk kota batas pertanian (agro-development frontier) dan kota batas sungai (water frontier).

\section{DAFTAR PUSTAKA}

Barnett, Jonathan, 1981, An Introduction to Urban Design, Harper \& Row, Publishers, New York.

Budiharjo, Eko dan Djoko Sujarto, 1998, Kota yang Berkelanjutan, Dirjen Dikti, Jakarta.

Golany, Gideon S., 1995, Ethics and Urban Design: Culture, Form and Environment,

, Nugroho dkk, 1992, Sejarah Nasional Indonesia III, Balai Pustaka, Jakarta.
Ngadijo, 1993, Sejarah dan Budaya Keraton Surakarta Hadiningrat, Tiga Serangkai, Surakarta.

Priyatmono, Alfa P., Studi Kecenderungan Perubahan Morfologi Kawasan di Kampung Laweyan Surakarta, Thesis S-2 UGM, Yogyakarta.

Qurtuby, John Wiley \& Sons Inc., New York.

Gosling, David \& Barry Maitland, 1984, Concept of Urban Design, Academy Edition, London.

Kusumastuti, 2004, Morfologi Kota Konflik: Solo, Makalah Seminar, Solo.

Kostof, Spiro, 1991, The City Shaped: Urban Patterns and Meanings Through History, Thames and Hudson, London.

Krier, Rob, 1984, Urban Space, Academy Edition, London.

Lombard, Denys, 2005, Nusa Jawa (Jilid 1-3), Gramedia, Jakarta.

Margana, S., 2004, Kraton Surakarta dan Yogyakarta 1769-1874, Pustaka Pelajar, Yogyakarta.

Muller, Dominique Gauzin, 2002, Sustainable Architecture and Urbanism: Concept,

Technologies and Examples, Birkhauser, Basel.

Muljana, Slamet, 1968, Runtuhnya Kerajaan Hindu dan Timbulnya Kerajaan-Kerajaan Islam di Nusantara,Bhratara, Jakarta.

NotosusantoSumanto Al, 2003, Arus Cina-IslamJawa, Inspeal Ahimsakarya Press, Yogyakarta.

Ronald, Arya, 2005, Nilai-Nilai Arsitektur Rumah Tradisional Jawa, GMU Press, Yogyakarta.

Sajid, R.M., 1984, Babad Sala, Rekso Pustoko, Solo.

Sudibjo, 1980, Babad Tanah Jawi, Departemen P dan K, Jakarta.

Sumalyo, Yulianto, 1993, Arsitektur Kolonial Belanda di Indonesia, GMU Press, Yogyakarta.

Vorstensteden, 1998, Djokja en Solo, Asia Maior, Purmerend.

Zahnd, Markus, 1999, Perancangan Kota Secara Terpadu, Kanisius Yogyakarta. 